\begin{tabular}{|c|l|}
\hline Title & $\begin{array}{l}\text { Characterization of Binding Between the Rat Small Intestinal Brush-border Membrane and Dietary Proteins in the } \\
\text { Sensory Mechani sm of Luminal Dietary Proteins. }\end{array}$ \\
\hline Author(s) & Hira, Tohru; Hara, Hiroshi; Tomita, Fusao \\
\hline Citation & $\begin{array}{l}\text { Bioscience Biotechnology and Biochemistry, 65(5), 1007-1015 } \\
\text { https://doi.org/10.1271/bbb.65.1007 }\end{array}$ \\
\hline Issue Date & 2001-05 \\
\hline Doc URL & http:/hdl.handle.net/2115/15861 \\
\hline Type & article \\
\hline File Information & BB\&B65-5.pdf \\
\hline
\end{tabular}

Instructions for use 


\title{
Characterization of Binding Between the Rat Small Intestinal Brush-border Membrane and Dietary Proteins in the Sensory Mechanism of Luminal Dietary Proteins
}

\author{
Tohru Hira, Hiroshi Hara, ${ }^{\dagger}$ and Fusao Tomita \\ Division of Applied Bioscience, Graduate School of Agriculture, Hokkaido University, Kita-9, Nishi-9, \\ Kita-ku, Sapporo 060-8589, Japan
}

Received July 10, 2000; Accepted December 22, 2000

\begin{abstract}
Dietary proteins are recognized by the gastrointestinal tract to display physiological functions, however, the sensory mechanism of the intestinal mucosa is not known. We examined binding properties between the rat small intestinal brush-border membrane (BBM) and proteins by using a surface plasmon resonance biosensor. BBM and solubilized BBM prepared from the rat jejunum bound to casein immobilized on the sensor surface, but not to bovine serum albumin. The ileal BBM showed less binding to casein than the jejunal BBM. Solubilized BBM binding to immobilized $\alpha$-casein was slightly inhibited by aminopeptidase inhibitors, but still more inhibited by addition of casein with the inhibitors. Guanidinated casein inhibited the solubilized BBM binding to $\alpha$-casein more strongly than casein (casein sodium and $\alpha$-casein) inhibited. Trypsinization of solubilized BBM abolished its binding activity to $\alpha$-casein. These results indicate that some membrane protein, but not aminopeptidases, contained in BBM interacts with dietary proteins, and that guanidinated casein has a higher affinity for BBM than intact casein. These binding intensities for proteins were closely correlated to physiological responsiveness, and are possibly involved in a sensory system for dietary protein in the intestine.
\end{abstract}

Key words: dietary protein; brush-border membrane; casein; binding

Nutrients regulate various physiological functions in the gastrointestinal tract through enteric nervous and enteroendocrine systems, so that ingested nutrients are effectively digested, absorbed, and utilized as rebuilding materials and energy for the body. ${ }^{1-3)}$ For example, glucose stimulates insulin secretion through gastric inhibitory polypeptide release, and fat and protein induce bile and pancreatic enzyme secretion through cholecystokinin (CCK) release, to facilitate uptake of themselves. These enteric hormones are released from endocrine cells lining in the intestinal mucosa as the result of recogniz- ing luminal nutrients in the intestine. Many studies on digestive and absorptive mechanisms for individual nutrients had been done. However, the mechanism for sensing nutrients by the intestinal epithelium is not well known.

Recently, it has been demonstrated that dietary proteins stimulated CCK release from isolated intestinal cells, ${ }^{4,5)}$ and from CCK-producing enteroendocrine cell line STC-1.67) These reports indicate that dietary proteins directly interact with intestinal epithelial cells including the CCK-producing enteroendocrine cells, and then trigger physiological responses. It is possible that there is a novel mechanism that the binding between luminal dietary proteins and the apical membrane of epithelial cells governs the gastrointestinal response. Traditional and specific receptors, membrane enzymes, transporters, or membrane structures may mediate the novel mechanism.

In this study, we tested whether dietary proteins bind with the intestinal brush-border membrane, and characterized the properties of the binding between various proteins and the brush-border membrane (BBM) by using a surface plasmon resonance (SPR)biosensor.

\section{Materials and Methods}

Equipment and reagents. Surface plasmon resonance-biosensor (BIACORE 3000 system) and Sensor chip CM5 were purchased from Biacore AB, Uppsala, Sweden. This system can detect and monitor the binding between an immobilized molecule (ligand) on the sensor surface and an injected molecule (analyte) over the sensor surface. Casein sodium from Wako Pure Chemical Ind., Osaka, Japan. $\alpha$ Casein, bovine serum albumin (BSA), Triton X-100 (reduced), trypsin (EC 3.4.21.4, type I from bovine pancreas), amastatin, and bestatin were from Sigma Chemical Co., St. Louis MO, U.S. Guanidinated

\footnotetext{
$\uparrow$ To whom correspondence should be addressed. Hiroshi HARA, Fax: +81-11-706-2504; E-mail: hara@chem.agr.hokudai.ac.jp Abbreviations: BBM, brush-border membrane; SBBM, solubilized brush-border membrane; API, aminopeptidase inhibitor
} 
casein, the lysine residues of which were converted to homoarginine, was prepared by previously described method. ${ }^{8,9)}$

Rat small intestinal brush-border membrane (BBM) preparation. Brush-border membrane (BBM) vesicles were prepared from male Sprague Dawley rats weighing about 200-300 g (Japan SLC, Hamamatsu, Japan) fed a laboratory chow (CE-2; Clea Japan inc., Tokyo, Japan), by the $\mathrm{CaCl}_{2}$ precipitation technique at $4^{\circ} \mathrm{C}$ with minor modifications. ${ }^{10,11)}$ The small intestine was excised and divided into the jejunum and ileum segments by cutting equally the length from the ligament of Treitz to the ileocecal junction. After rinsing of the intestinal lumen with ice cold saline and wiping debris off, the mucosa was removed by gentle scraping with a glass slide and collected in $10 \mathrm{ml}$ of buffer $1(50 \mathrm{~mm}$ mannitol, $2 \mathrm{~mm}$ Tris/ $\mathrm{HCl}, \mathrm{pH} \mathrm{7.1)}$ on ice. The mucosal scraping was homogenized with 10 strokes of motorized glass/Teflon (Potter-Elvehjem) homogenizer at high speed (setting no. 10, EYELA Mini D. C Stirrer; Tokyo Rikakikai co., Tokyo, Japan) and then with a Polytron homogenizer (Kinematica, Lucerne, Switzerland) for $30 \mathrm{sec}$ at setting no. 6. Solid $\mathrm{CaCl}_{2}$ was added to final concentration of $10 \mathrm{~mm}$ and the preparation was rehomogenized for additional $20 \mathrm{sec}$ with a Polytron homogenizer. The mixture was placed on ice for $15 \mathrm{~min}$ and then centrifuged at $12,000 \mathrm{~g}$ for $5 \mathrm{~min}$ (Hitachi 55P-72 ultracentrifuge; Hitachi-koki, Hitachinaka, Japan). The supernatant was centrifuged at $48,000 \mathrm{~g}$ for $20 \mathrm{~min}$. The resultant pellet was suspended in $1 \mathrm{ml}$ of buffer $2(50 \mathrm{~mm}$ mannitol, $10 \mathrm{mM}$ Tris $/ \mathrm{HCl}, \mathrm{pH} 7.5)$, homogenized with 10 strokes with a Potter-Elvehjem homogenizer, and centrifuged at $48,000 \mathrm{~g}$ for $20 \mathrm{~min}$. The vesicle pellet was resuspended in $1 \mathrm{ml}$ of buffer 3 (10 mM HEPES/ Tris, $\mathrm{pH} 7.1$ ) and homogenized with 10 strokes with the Potter-Elvehjem homogenizer. Solid KSCN was then added to a concentration of $0.6 \mathrm{M}$, and the mixture was homogenized with an additional 10 strokes, placed on ice for $20 \mathrm{~min}$, diluted 1:10 with buffer 3, and placed on ice for $20 \mathrm{~min}$ more. After centrifugation at $6,000 \mathrm{~g}$ for $10 \mathrm{~min}$, the supernatant was spun at $38,000 \mathrm{~g}$ for $30 \mathrm{~min}$. The resultant pellet was rehomogenized in $1 \mathrm{ml}$ of HBS-E buffer $(10 \mathrm{mM}$ HEPES, $0.15 \mathrm{M} \mathrm{NaCl}, 3 \mathrm{~mm}$ EDTA, pH 7.4), then stored at $-80^{\circ} \mathrm{C}$ until the biosensor analysis.

Solubilization of brush-border membrane. The brush-border membrane vesicles pooled from 6 rats were solubilized by a detergent Triton X-100. Briefly, Triton X-100 was added to pooled BBM at a concentration of $0.1 \%$, and the preparation was shaken gently $(100 \mathrm{rpm})$ at $4^{\circ} \mathrm{C}$ for $60 \mathrm{~min}$ by using a Vortex shaker (VR-36D; Taitec, Saitama, Japan). The solution was centrifuged at $100,000 \mathrm{~g}$ for $90 \mathrm{~min}$, and the supernatant was collected as the solubilized BBM
(SBBM). This was divided into portions and stored at $-80^{\circ} \mathrm{C}$ until the biosensor analysis, and then diluted 1:10 with HBS-E buffer before the analysis (Triton $\mathrm{X}-100$ final conc.; $0.01 \%$ ). In preliminary examinations, the concentration of Triton X-100 at $0.1 \%$ was optimal in the binding activity to immobilized proteins compared with higher $(1 \%)$ or lower $(0.01$, $0.05 \%$ ) concentrations, so we used Triton X-100 at $0.1 \%$ for the solubilization of BBM. Protein concentrations of BBM and SBBM were measured by the Bio-Rad protein assay method (Bio-Rad, California, U.S.).

\section{Biosensor analysis.}

Immobilization of proteins. Proteins (casein sodium, $\alpha$-casein, BSA) were immobilized onto the sensor surface (flow-cell) of Sensor chip CM5 using a mixture of $N$-ethyl- $N^{\prime}$-dimethylaminopropylcarbodiimide and $N$-hydroxysuccinimide in the amine coupling kit (Biacore) according to previously described principles. ${ }^{12,13)}$ Casein sodium $(40 \mu \mathrm{g} / \mathrm{ml}$ in $10 \mathrm{~mm}$ acetate buffer, $\mathrm{pH} 4.0), \alpha$-Casein $(40 \mu \mathrm{g} / \mathrm{ml}$ in $10 \mathrm{~mm}$ acetate buffer, $\mathrm{pH} 4.0)$, BSA $(40 \mu \mathrm{g} / \mathrm{ml}$ in $10 \mathrm{mM}$ acetate buffer, $\mathrm{pH} 5.0$ ) were respectively injected over the activated sensor surface using the surface preparation wizard in a software BIACORE Control 3.0 (Biacore). After coupling, the activated surface was blocked by the injection of $0.1 \mathrm{M}$ ethanolamine ( $\mathrm{pH}$ 8.0). As a blank flow-cell, ethanolamine was immobilized by a single injection of $0.1 \mathrm{M}$ ethanolamine $(\mathrm{pH} 8.0)$ over the activated sensor surface without a protein injection.

Binding study. BBM and SBBM were injected as "analyte" over the sensor surface on which a protein was immobilized. All analysis were done using HBSE buffer (10 mM HEPES, $0.15 \mathrm{M} \mathrm{NaCl}, 3 \mathrm{~mm}$ EDTA, $\mathrm{pH}$ 7.4) as a running buffer, at the flow rate $10 \mu \mathrm{l} / \mathrm{min}$, and at the temperature $25^{\circ} \mathrm{C}$. Analytes were injected for $2 \mathrm{~min}$, and injections were repeated 2-4 times in each analysis.

Experiment 1. BBM binding to immobilized proteins. We found whether BBM bound to immobilized proteins. BBM was diluted with HBS-E buffer (10-200 $\mu$ g protein $/ \mathrm{ml}$, and then BBM was injected over the sensor surface on which casein sodium, BSA, $\alpha$-casein was immobilized respectively. In addition, BBM was prepared from the ileum as described above, and the ileal BBM was injected over the protein-immobilized sensor surface to compare binding activities with the jejunal BBM.

Experiment 2. Solubilized BBM binding to immobilized proteins. It was found whether solubilized BBM (SBBM) bound to immobilized proteins. SBBM was diluted $(5-30 \mu \mathrm{g}$ protein $/ \mathrm{ml})$ with $\mathrm{HBS}-\mathrm{ET}$ buffer (HBS-E buffer containing $0.01 \%$ Triton 
$\mathrm{X}-100$ ), and then injected over the protein-immobilized sensor surface.

Experiment 3. Effects of trypsinization of $S B B M$ for its binding to immobilized proteins. To find whether the binding between SBBM and $\alpha$-casein was due to a protein-protein interaction or not, SBBM was treated with trypsin. Trypsin was added to SBBM solution at the protein concentration ratio of $1: 100$, and the mixture was immediately incubated at $37^{\circ} \mathrm{C}$ for $60 \mathrm{~min}$, or placed on ice. Trypsin treated- or trypsin free-SBBM $(10 \mu \mathrm{g} / \mathrm{ml})$ were injected over the $\alpha$-casein-immobilized sensor surface as described above.

Experiment 4. Effects of different buffer compositions for the dissociation of SBBM bound to immobilized $\alpha$-casein. It was found what kind of interactions (ionic-, hydrogen-, hydrophobic-bond) contributed to the binding between SBBM and $\alpha$-casein, by using buffers with different compositions for dissociating SBBM bound to $\alpha$-casein on a sensor surface. We used HBS-E buffer (10 mM HEPES, $0.15 \mathrm{M} \mathrm{NaCl}$, $3 \mathrm{~mm}$ EDTA, $\mathrm{pH}$ 7.4) as a control, HBS-E buffer containing ethanol $(5,10,20 \% \mathrm{v} / \mathrm{v})$ to weaken hydrophobic-bond, HBS-E buffer containing urea (1, $2,3 \mathrm{M})$ to weaken hydrogen-bond, HBS-E buffer containing $\mathrm{NaCl}(0.5,1.03 .0 \mathrm{M})$ to weaken ionic- bonds, Tris buffer $(0.5 \mathrm{M} \mathrm{NaCl}, 0.1 \mathrm{M}$ Tris-HCl, $\mathrm{pH} 8.5)$ or sodium acetate buffer $(0.5 \mathrm{M} \mathrm{NaCl}, 0.1 \mathrm{M}$ sodium acetate, $\mathrm{pH} 4.5) .^{14)}$ These buffers were injected for 3 min immediately after finishing the SBBM injection, by using the "co-inject" command in the Biacore system. Rates of SBBM remained on the $\alpha$ casein surface after injections of these solutions (at $315 \mathrm{sec}$ ), were evaluated as percentage relative to peak amount of SBBM (at $110 \mathrm{sec}$ ) bound to $\alpha$ casein.

Experiment 5. Effects of aminopeptidase inhibitors, and competitive effects of proteins (casein sodium, $\alpha$-casein, and guanidinated casein), for the SBBM binding to immobilized casein. Aminopeptidases are proteolytic enzymes localized at the brushborder membrane, so it was possible that they might contribute to the binding between BBM and proteins. To assess this possibility, two aminopeptidase inhibitors were tested as to whether they inhibit the SBBM binding to immobilized casein. Amastatin (10, $100 \mu \mathrm{g} / \mathrm{ml}$ ), a specific inhibitor for aminopeptidase A and leucine aminopeptidase (LAP), and/or bestatin $(10,100 \mu \mathrm{g} / \mathrm{ml})$, a specific inhibitor for aminopeptidase B and LAP, were added to the SBBM $(10 \mu \mathrm{g}$ protein $/ \mathrm{ml}$ ) solution.

In addition, we examined inhibitory effects of nonimmobilized proteins ( $\alpha$-casein , guanidinated casein) for the binding between SBBM and immobilized $\alpha$ casein to compare intensities of binding between
SBBM and these proteins. Alpha-casein or guanidinated casein $(25-200 \mu \mathrm{g} / \mathrm{ml})$ was added to SBBM $(10 \mu \mathrm{g}$ protein $/ \mathrm{ml})$ solution.

Finally, we examined inhibitory effects of nonimmobilized proteins ( $\alpha$-casein, casein sodium, and guanidinated casein) for the binding between SBBM and $\alpha$-casein under the condition that aminopeptidase activities were eliminated. In this experiment, a sufficiently high concentration of the inhibitors (amastatin and bestatin, $100 \mu \mathrm{g} / \mathrm{ml}$ each) was mixed with SBBM $(10 \mu \mathrm{g}$ protein $/ \mathrm{ml})$, and proteins $(100 \mu \mathrm{g} / \mathrm{ml})$ were further added. Also, $100 \mu \mathrm{g} / \mathrm{ml}$ of aminopeptidase inhibitors was further added to SBBM containing aminopeptidase inhibitors (total $200 \mu \mathrm{g} / \mathrm{ml}$ ) to compare the inhibitory activity of protein with that of aminopeptidase inhibitors itself. SBBM containing aminopeptidase inhibitors and/or proteins, were injected over the $\alpha$-casein-immobilized sensor surface as described above.

Data analysis. The amount of BBM and SBBM bound to immobilized protein (resonance unit; RU) was calculated by subtraction of the blank flow-cell response from the protein immobilized flow-cell response. In experiment 5 , the binding amounts of SBBM containing test agents (proteins, aminopeptidase inhibitors) were represented as percentages relative to that of solubilized BBM without test agents. Significant differences among mean values were evaluated by the Duncan's multiple range test $(P<0.05)$.

\section{Results}

Figure 1-a shows overlaid sensorgrams (changes of surface plasmon resonance signal) of casein sodiumimmobilized surface in response to injections of various concentrations of BBM (expressed as "BBM protein conc." in figures). The BBM injection onto immobilized casein sodium showed binding signals with definite association and dissociation curves, and amounts (RU) of BBM bound to casein sodium were increased in response to increasing protein concentrations of BBM. BBM were injected over an $\alpha$-caseinor BSA-immobilized flow-cell, as well as casein sodium-immobilized flow-cell as shown in Fig. 1-b. BBM bound to $\alpha$-casein in a dose-dependent manner as well as to casein sodium. Sensorgrams of the $\alpha$ casein surface injected with BBM showed binding signals similar to the casein sodium surface. Although the immobilization levels of these proteins were almost the same casein sodium; $5150 \mathrm{RU}, \alpha$ casein; $5404 \mathrm{RU}, \mathrm{BSA}$; $6349 \mathrm{RU}$ (1 RU=1 pg/mm² sensor surface in a flow-cell)\}, BBM bindings to immobilized BSA were apparently lower than bindings to casein sodium and $\alpha$-casein, and dose-responses were not observed.

Bindings of the ileal BBM to immobilized proteins are shown in Fig. 2. Amounts of ileal BBM bound to 
immobilized casein sodium and $\alpha$-casein were increased with increasing BBM protein concentrations injected as analytes. However, amounts of ileal BBM bound to immobilized casein sodium or $\alpha$-casein were apparently lower than those of jejunal BBM. As well as jejunal BBM, amounts of ileal BBM bound to immobilized BSA were lower than those to immobilized casein sodium and $\alpha$-casein.

Solubilized BBM (SBBM) also showed binding signals to $\alpha$-casein-immobilized sensor surface similarly to unsolubilized BBM, and amounts of binding increased depending on the protein concentration of SBBM (Fig. 3-a). Comparisons of SBBM bindings to immobilized casein sodium, $\alpha$-casein, and BSA are shown in Fig. 3-b. Amounts of BBM binding were corrected by each immobilized protein level (expressed as "binding amounts of SBBM/1000 RU of immobilized ligand"' in the figure), because immobilized levels were different between each proteins, not as well as experiment 1 and 2 . Binding amounts of SBBM to immobilized $\alpha$-casein tended to be higher

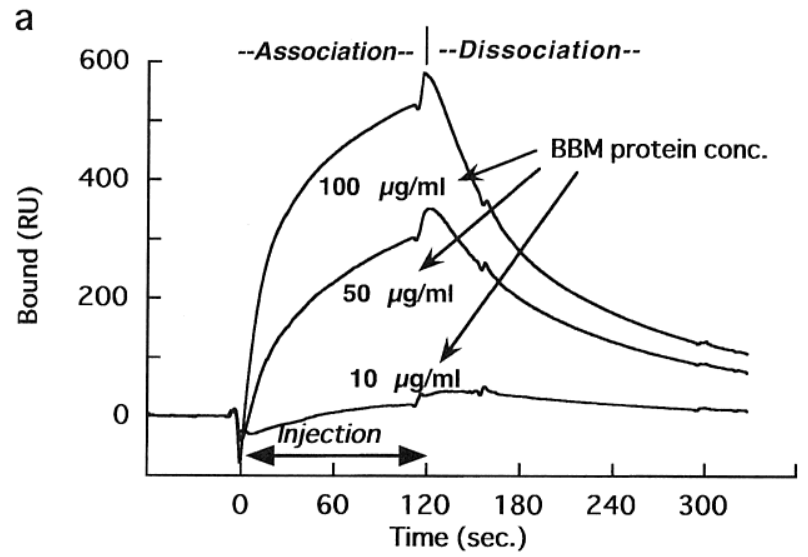

b

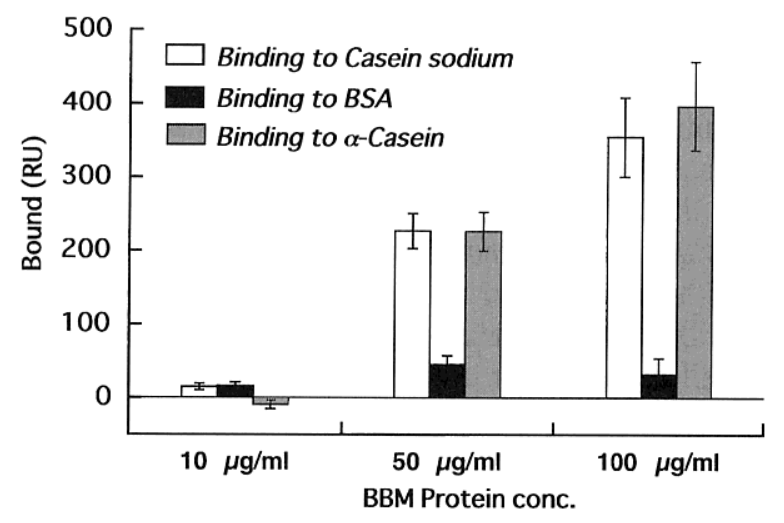

Fig. 1. Brush-border Membrane (BBM) Bound to Casein Sodium and $\alpha$-casein, but not BSA.

(a) Overlaid sensorgrams of casein sodium-immobilized surface in response to injections of various BBM concentrations. (b) Binding responses (resonance unit; RU) of protein-immobilized surface in response to various concentrations of BBM. (open column; casein sodium, closed column; BSA, hatched column; $\alpha$-casein) Values are means \pm SEM obtained from 4 repeated injections.

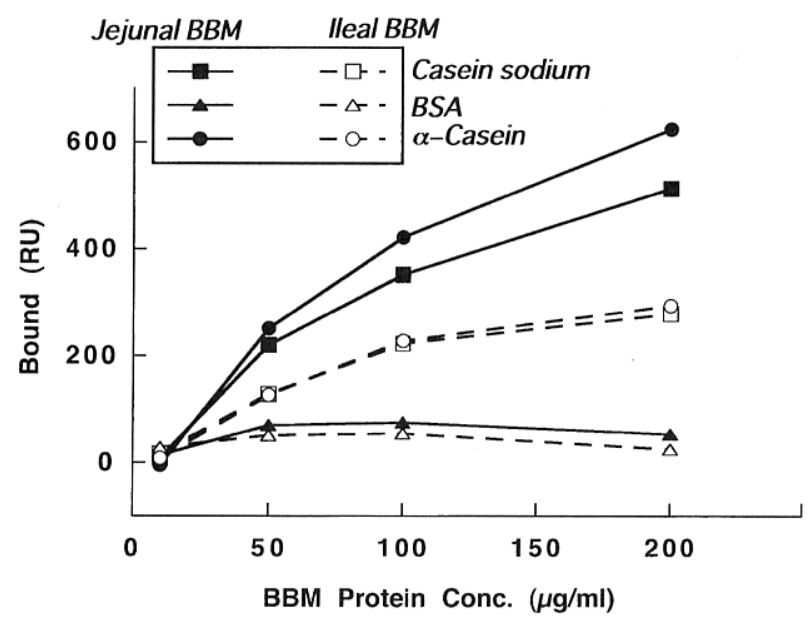

Fig. 2. Less Binding Activities of Ileal BBM than Jejunal BBM. Binding responses of protein-immobilized surface in response to increasing concentrations of the jejunal (solid lines) or ileal BBM (dotted lines). Values are means of 4 repeated injections.

a

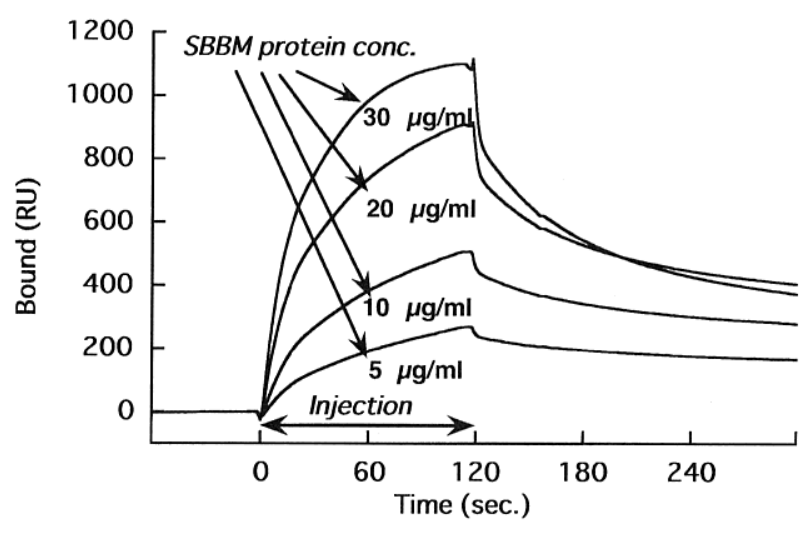

b

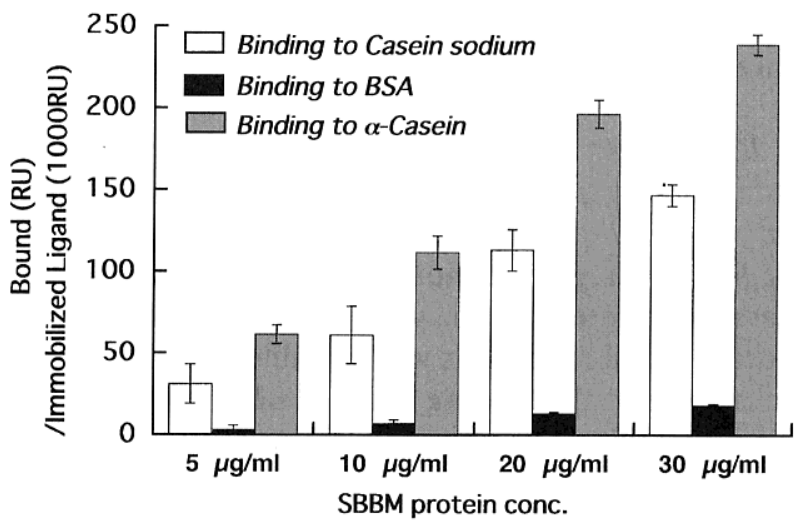

Fig. 3. Binding of the Solubilized BBM (SBBM) to Proteins Immobilized on the Sensor Surface.

(a) Overlaid sensorgrams of $\alpha$-casein-immobilized surface in response to injections of various SBBM concentrations. (b) Binding responses (resonance unit; RU) of protein-immobilized surface in response to increasing concentrations of SBBM. (open column; casein sodium, closed column; BSA, hatched column; $\alpha$-casein) Values are means \pm SEM obtained from 4 repeated injections. 
than those to casein sodium, and the binding to BSA were apparently lower than those to casein sodium and $\alpha$-casein.

In experiment $3-5$, we used $\alpha$-casein, one of the major components of casein, as a "ligand" because it was a more purified protein than casein sodium, and the most potent ligand bound by SBBM, as shown in Fig. 3-b.

SBBM treated with trypsin showed a marked decrease in the binding to immobilized $\alpha$-casein, as shown in Fig. 4. Trypsin treatment of SBBM on ice reduced the binding by over $40 \%$, and that at $37^{\circ} \mathrm{C}$ for $60 \mathrm{~min}$ completely abolished the binding activity.

Figure 5-a shows overlaid sensorgrams of $\alpha$-caseinimmobilized surface when various buffers were injected immediately after SBBM injections. After these buffers were injected, amounts of SBBM remained on the $\alpha$-casein surface (at $315 \mathrm{sec}$ ) were different among buffer compositions. That is, amounts of remaining SBBM after injections of HBS-E containing $5 \%$ ethanol or HBS-E containing $3.0 \mathrm{M} \mathrm{NaCl}$ were higher, and that after the injection of HBS-E containing $3.0 \mathrm{M}$ urea was lower, than that after the injection of HBS-E buffer. These results indicate $3.0 \mathrm{M}$ urea is more effective, but $5 \%$ ethanol and $3.0 \mathrm{M} \mathrm{NaCl}$ was less effective, for dissociating SBBM from $\alpha$-casein, than HBS-E buffer. Rates of remaining SBBM relative to peak amounts of SBBM bound to $\alpha$-casein were shown in Fig. 5-b. HBS-E buffer containing ethanol showed a dose-dependent decrease in the rate of remaining SBBM, and concentration of a $20 \%$ was more effective for dissociating SBBM than HBS-E buffer. Urea contained in HBS-E buffer also caused dose-dependent reduction of remaining SBBM rate. At all concentrations tested, urea was more effective for dissociating SBBM from

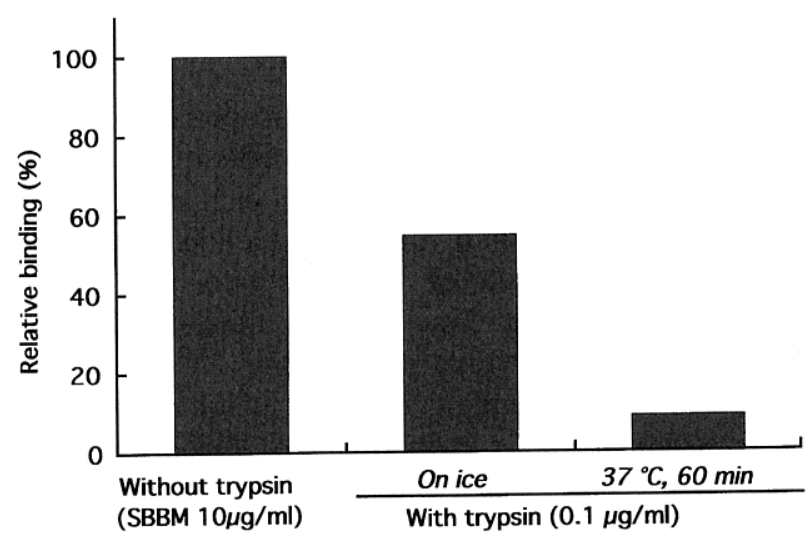

Fig. 4. Trypsinization of SBBM Abolished Its Binding to Immobilized $\alpha$-Casein.

SBBM $(10 \mu \mathrm{g} / \mathrm{ml})$ mixed with trypsin $(0.1 \mu \mathrm{g} / \mathrm{ml})$ were treated at $37^{\circ} \mathrm{C}$ for $60 \mathrm{~min}$, or placed on ice. Trypsin treated- or nontreated-SBBM was injected over the $\alpha$-casein-immobilized sensor surface. Values are expressed as percentage (\%) of the binding of trypsin free SBBM, and are means of 4 repeated injections. $\alpha$-casein than HBS-E buffer. HBS-E containing in-

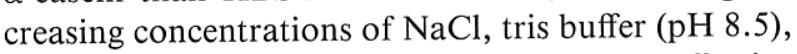
or sodium acetate buffer ( $\mathrm{pH} 4.5$ ) were less effective for the dissociation than HBS-E buffer.

SBBM bindings to $\alpha$-casein inhibited by aminopeptidase inhibitors, $\alpha$-casein, guanidinated casein were shown in Fig. 6-a. Amastatin at 10 and $100 \mu \mathrm{g} / \mathrm{ml}$ decreased by $7 \%$ and $15 \%$ of SBBM binding to $\alpha$ casein, respectively. Both concentrations of bestatin decrease SBBM binding no more than 10\%. Simultaneous additions of both inhibitors showed slightly decreased SBBM binding similarly with a single addition of amastatin. The inhibitory effect of $\alpha$-casein added to SBBM was dose-dependent, and stronger than aminopeptidase inhibitors. Additions of guanidinated casein, the lysine residues of which

a

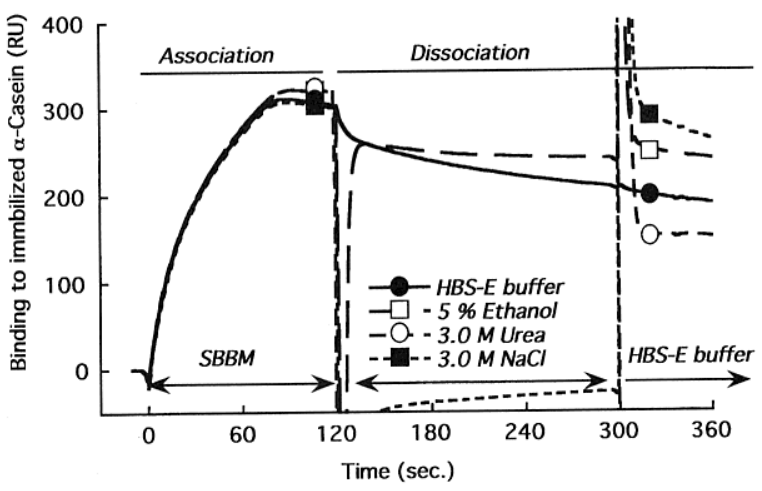

b

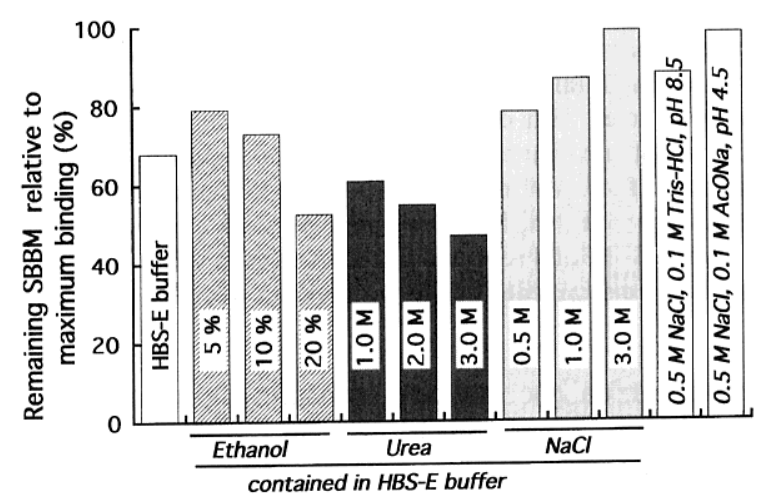

Fig. 5. Changes in the Amounts of SBBM Bound to Immobilized $\alpha$-Casein after Injections of Various Solutions.

(a) Overlaid sensorgrams of $\alpha$-casein-immobilized surface in response to co-injections of SBBM and some solutions. Ethanol, urea, $\mathrm{NaCl}$ was added to HBS-E buffer at various concentrations described below. (b) Rates of remaining SBBM (at $315 \mathrm{sec}$ ) on the $\alpha$-casein surface relative to peak values (at $110 \mathrm{sec}$ ). As soon as SBBM $(10 \mu \mathrm{g} / \mathrm{ml}, 10 \mu \mathrm{l} / \mathrm{min}$ for $2 \mathrm{~min})$ injections were finished, solutions listed below were injected for $3 \mathrm{~min}$ $(10 \mu \mathrm{l} / \mathrm{min})$. HBS-E buffer (10 mM HEPES, $0.15 \mathrm{~m} \mathrm{NaCl}, 3 \mathrm{~mm}$ EDTA, pH 7.4, open column), HBS-E buffer containing ethanol $(5-20 \%$, hatched column), urea $(1-3 \mathrm{M}$, gray column), $\mathrm{NaCl}$ $(0.5-3.0 \mathrm{M}$, dotted column), tris buffer $(0.1 \mathrm{M}$ tris, $0.5 \mathrm{M} \mathrm{NaCl}$, $\mathrm{pH} 8.5)$, sodium acetate buffer $(0.1 \mathrm{~m}$ sodium acetate, $0.5 \mathrm{~m}$ $\mathrm{NaCl}, \mathrm{pH} 4.5$ ). Values are means of 2 or 3 repeated injections. 


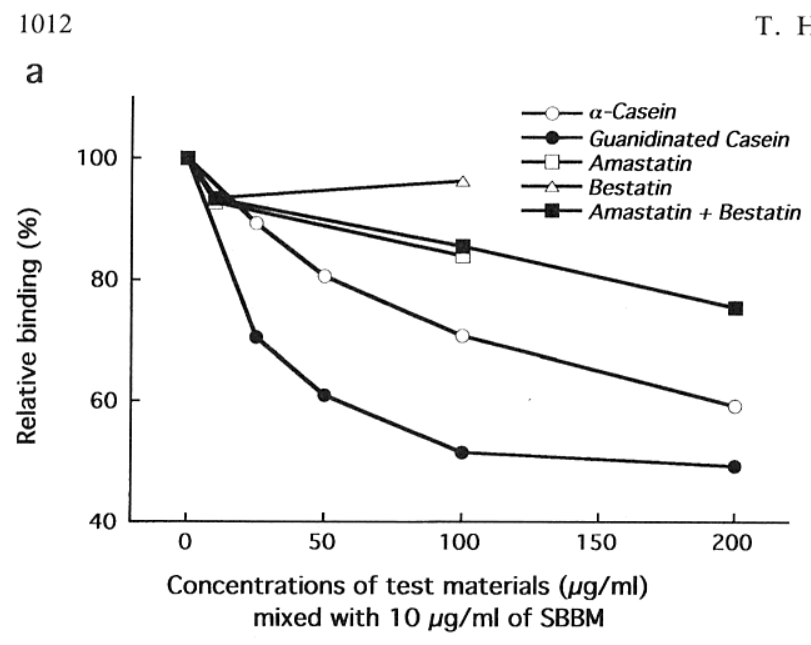

T. HiRA et al.

b

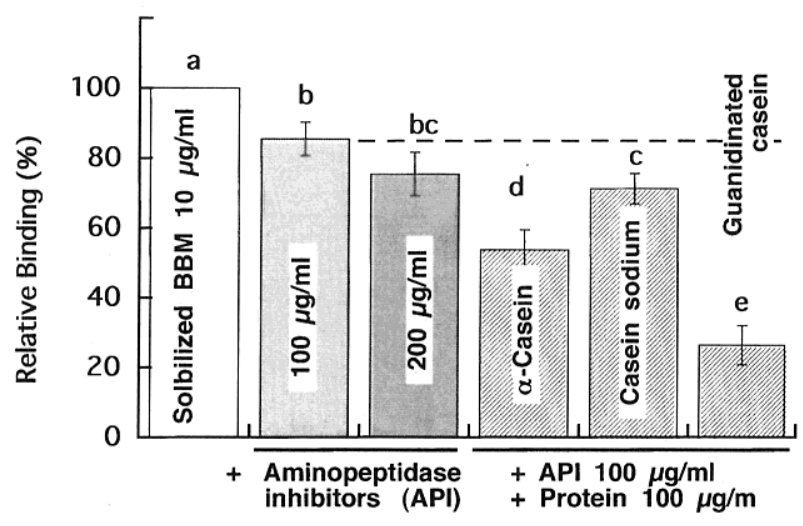

Fig. 6. Competitive Inhibition of Non-immobilized Proteins ( $\alpha$ Casein, Casein Sodium or Guanidinated Casein) and/or Aminopeptidase Inhibitors (API; Amastatin and/or Bestatin) for the SBBM Binding to Immobilized $\alpha$-Casein.

(a) $\mathrm{SBBM}(10 \mu \mathrm{g}$ protein $/ \mathrm{ml})$ with or without proteins $(25-200 \mu \mathrm{g} / \mathrm{ml})$, API $(10-200 \mu \mathrm{g} / \mathrm{ml})$ were injected over $\alpha$ casein-immobilized sensorsurface. (b) SBBM $(10 \mu \mathrm{g} / \mathrm{ml})$ containing API (amastatin and bestatin $100 \mu \mathrm{g} / \mathrm{ml}$ respectively) were injected with or without protein $(100 \mu \mathrm{g} / \mathrm{ml}$ of $\alpha$-casein, casein sodium, guanidinated casein) over $\alpha$-casein-immobilized sensorsurface. Values are expressed as percentages (\%) of the binding amount of SBBM without proteins and API, and are means \pm SEM of 4 repeated injections. Mean values not sharing a letter are significantly different between treatments $(P<0.05)$.

were chemically converted to homoarginine residues, caused dose-dependent inhibition for the binding between SBBM and $\alpha$-casein, and were more effective than the addition of $\alpha$-casein, apparently.

Inhibitory effects of some proteins for SBBM binding to immobilized $\alpha$-casein with aminopeptidase activities eliminated were shown in Fig. 6-b. The amount of SBBM bound to immobilized $\alpha$-casein was reduced about $15 \%$ by addition of $100 \mathrm{~g} / \mathrm{ml}$ of aminopeptidase inhibitors (amastatin and bestatin). Further addition $(100 \mu \mathrm{g} / \mathrm{ml})$ of the inhibitors (total $200 \mu \mathrm{g} / \mathrm{ml}$ ) reduced SBBM binding by $20 \%$. Additions of $100 \mu \mathrm{g} / \mathrm{ml}$ of casein sodium or $\alpha$-casein to SBBM containing the inhibitors $(100 \mu \mathrm{g} / \mathrm{ml})$ reduced about $30 \%$ or $40 \%$ of SBBM bindings to immobilized $\alpha$-casein, respectively. The addition of guanidi-

nated casein reduced $70 \%$ of SBBM binding to immobilized $\alpha$-casein, and the binding of SBBM containing guanidinated casein was significantly lower than those containing casein sodium or $\alpha$-casein.

\section{Discussion}

To study the sensory mechanism of dietary protein in the gastrointestinal tract, properties of binding between rat small intestinal brush-border membrane $(\mathrm{BBM})$ and dietary proteins were analyzed by using the surface plasmon resonance biosensor BIACORE 3000. This is the first study directed to the binding between the intestinal brush-border membrane and dietary proteins. It has been explained that dietary proteins in the intestinal lumen are recognized by the feedback mechanism in the control of the exocrine pancreatic secretion. ${ }^{15-17)}$ In this mechanism, the endogenous CCK-releasing peptides (CCK-RP) but not dietary proteins, act directly to intestinal epithelial cells. ${ }^{18-20)}$ However, specific receptors for the endogenous CCK-RP have not been identified yet. ${ }^{21-23)}$ In contrast, we and other investigators demonstrated that proteins were recognized in the intestinal lumen independent of the feedback mechanism, and these reports indicate that proteins could act directly to intestinal epithelial cells including CCK producing enteroendocrine cells. ${ }^{6,24-26)}$

In this study, as a low denatured condition, BBM were used as "analyte" in the mobile phase, and proteins were immobilized on the sensor surface as "ligand" in the BIACORE system, for two reasons. First, if BBM or SBBM was immobilized on the sensor surface as "ligand", BBM or SBBM was possibly denatured by exposure to low $\mathrm{pH}$ buffer $(10 \mathrm{~mm}$ acetate, $\mathrm{pH} 4 \sim 6$ ) in the general immobilization procedure. Second, in the case of using heterogeneous materials such as BBM or SBBM for the "ligand", all of components in BBM may not be immobilized enough and equally. We evaluated the amount of binding (RU) to assess properties of binding between BBM and dietary proteins in all experiments because the affinity constant (such as $\mathrm{K}_{\mathrm{A}}$ or $\mathrm{K}_{\mathrm{D}}$ ) can be evaluated only by using a homologous analyte the molecular weight of which is known.

As shown in Fig. 1-a, rat small intestinal BBM bound to casein sodium immobilized on sensor surface in a dose-dependent manner. BBM also bound to $\alpha$-casein, a major component of casein. In contrast, BBM did not bound to BSA that is used widely as a standard (general) protein but not as a dietary protein (Fig. 1-b). These results suggest that there are specific structures on casein and $\alpha$-casein to be bound as one of dietary proteins by rat small intestinal BBM. Such binding selectivity of BBM to casein or BSA corresponds with stimulative activities for cholecystokinin secretion from enteroendocrine cells ${ }^{6,7)}$ and in vivo activities for the increase of exo- 
crine pancreatic secretion in the previous studies. ${ }^{27,28)}$

The ileal BBM had less binding activities to casein and $\alpha$-casein than the jejunal BBM as shown in Fig. 2. This indicates that affinities for casein are higher in the jejunal BBM than in the ileal BBM, and this also corresponds to the in vivo result that the proteins are recognized by the proximal rather than the distal small intestine. ${ }^{29,30)}$

Solubilized BBM showed binding activities to casein and $\alpha$-casein, but not to BSA similarly with unsolubilized BBM (Fig. 3). As described in 'materials and methods', solubilization by $0.1 \%$ Triton X-100 was optimal for the biosensor analysis (data not shown). This finding indicates that one or some of solubilized components of BBM, without membrane structure, are potent to bind with casein.

The trypsinization (at $37^{\circ} \mathrm{C}$ for $60 \mathrm{~min}$ ) of SBBM abolished its binding to $\alpha$-casein (Fig. 4). This indicates that some membrane protein(s) hydrolyzed by trypsin are involved in the binding between SBBM and $\alpha$-casein, in other words, the binding is a proteinprotein interaction. This is supported by the fact that the boiling of SBBM (15 min) also abolished its binding activity to immobilized $\alpha$-casein (data not shown). Partial reduction of SBBM binding by on ice-mixing with trypsin, may be due to partial digestion of SBBM by trypsin for the period between mixing and injection to the biosensor.

It was found which kinds of forces contribute to the binding between SBBM and immobilized $\alpha$ casein, by using various buffer conditions for dissociating SBBM bound to $\alpha$-casein. As shown in Fig. 5, urea (1-3 M) and ethanol $(20 \%)$ were more effective than control (HBS-E) buffer. Since urea and ethanol, respectively weaken hydrogen bonds and hydrophobic bonds, it is suggested that the binding between SBBM and $\alpha$-casein consists of hydrogen and hydrophobic bonds.

Competitive inhibition by non-immobilized $\alpha$ casein for the binding between SBBM and immobilized $\alpha$-casein was demonstrated as shown in Fig. 6-a. This supports that responses detected by the biosensor represent the binding between SBBM and $\alpha$ casein immobilized on a sensor surface. Interestingly, guanidinated casein showed apparently further inhibition than $\alpha$-casein. The result that guanidinated casein inhibited the binding between SBBM and immobilized $\alpha$-casein, indicates that guanidinated casein bound to SBBM competitively with $\alpha$-casein. Furthermore, higher inhibitory effect of guanidinated casein than that of $\alpha$-casein indicates that guanidinated casein has a higher affinity for BBM than $\alpha$-casein. In this study, inhibitory activities were evaluated to compare SBBM binding activities of proteins (casein vs. guanidinated casein), because the immobilized guanidinated casein onto the sensor surface was unstable for repetitious binding assays, unlike casein sodium, $\alpha$-casein or BSA.
We found whether aminopeptidases contained in SBBM contribute to the binding between SBBM and $\alpha$-casein by using specific aminopeptidase inhibitors, amastatin and bestatin. Both inhibitors at the concentration of $10 \mu \mathrm{g} / \mathrm{ml}$ reduced the SBBM binding to $\alpha$-casein no more than $10 \%$ (Fig. 6-a), although the concentration of inhibitors was excessive $(>20$-fold of $\mathrm{IC}_{50}$ ) for complete inhibition of aminopeptidase activities. ${ }^{31)}$ This result indicates that the SBBM binding to $\alpha$-casein does not depend on aminopeptidases (aminopeptidase A, B, and leucine aminopeptidase). However, amastatin showed dose-dependent inhibition as shown in Fig. 6-a and 6-b, hence the BBM binding to $\alpha$-casein might be sensitive to amastatin. Possibly, the peptidemimetic structure and some side chain structures of amastatin were detected by some $\alpha$-casein-binding components of SBBM.

As shown in Fig. 6-b, additions of $\alpha$-casein or guanidinated casein $(100 \mu \mathrm{g} / \mathrm{ml})$ to SBBM the aminopeptidase activities of which were blocked by the excess of inhibitors (amastatin and bestatin, $100 \mu \mathrm{g} / \mathrm{ml}$ each), diminished the SBBM binding to immobilized $\alpha$-casein more than the further addition $(100 \mu \mathrm{g} / \mathrm{ml})$ of aminopeptidase inhibitors (total $200 \mu \mathrm{g} / \mathrm{ml}$ ). The addition of $100 \mu \mathrm{g} / \mathrm{ml}$ of casein sodium inhibited the SBBM binding almost equally with further addition of aminopeptidase inhibitors (total $200 \mu \mathrm{g} / \mathrm{ml}$ ). However, molar concentrations of $100 \mu \mathrm{g} / \mathrm{ml}$ casein (M. W. $>20,000$ ) were lower than that of aminopeptidase inhibitors (amastatin, M. W. 511 , bestatin, M. W. 344). Therefore, these results indicates that casein ( $\alpha$-casein, guanidinated casein and casein sodium) has far higher affinity to BBM than aminopeptidase inhibitors, and also support that aminopeptidases do not contribute to the binding between BBM and dietary proteins as described above.

As well as the result shown in Fig. 6-a, the addition of guanidinated casein inhibited SBBM binding significantly stronger than that of $\alpha$-casein under the condition that aminopeptidase activities were eliminated (Fig. 6-b). Guanidinated casein is a chemically modified protein that has higher bioactivity than intact casein in the small intestine, that is, the modified protein stimulated cholecystokinin release from mucosa and subsequent pancreatic enzyme secretion much higher than intact casein. ${ }^{5,9)}$ The finding indicated in this study supports that the binding of BBM to dietary proteins might be involved in the sensory mechanism for the proteins in the intestinal mucosa.

In the brush-border membrane, there could be one or some components involved in the sensory mechanism of dietary protein to exert physiological signaling by binding with dietary proteins. As a sensory mechanism, it is proposed the existence of specific receptors which detect some structural features of dietary proteins (not only $\alpha$-casein) on the surface of a specific cell such as CCK-producing enteroendo- 
crine cells. As another mechanism, it is possible that some low specific bindings or interactions of proteins to brush-border membrane are associated with the sensory mechanism. Recent reports demonstrated stimulatory effects of soybean lectins on CCK release and pancreatic exocrine secretion in rats. ${ }^{32,33)}$ It was suggested that lectins bind to glycoconjugates on the surface of intestinal epithelial cell brush-border membrane, and then trigger the release of CCK. Thus, we do not specify the existence of traditional receptors such as seventh-transmembrane proteins, and it may be possible that some unknown protein in the BBM such like proteolytic enzymes or glycoproteins plays a role of the "dietary protein receptor"'. In this study, we demonstrated some characteristics of the binding between BBM and protein that correspond with some physiological responses caused by recognition of dietary proteins in the gastrointestinal tract. This supports our hypothesis that dietary proteins interact directly with the intestinal mucosa to exert physiological functions. However, it requires further evidences to confirm the hypothesis, including the identification of putative receptor for dietary proteins localized at the brushborder membrane or the identification of some interaction between $\mathrm{BBM}$ and proteins for triggering physiological signals.

In conclusion, the rat small intestinal brush-border membrane (BBM) bound to dietary proteins. BBM bound to casein but not to BSA, and more to guanidinated casein, independent of aminopeptidases in BBM. Jejunal BBM had higher binding activities to casein than ileal BBM. These bindings consisted of protein-protein interactions between some protein (s) in the BBM and dietary protein. These binding intensities between proteins and BBM seems to correspond with physiological activities of proteins in the rat small intestine, so it is possible that these binding may mediate the sensory mechanism of dietary protein in the gastrointestinal tract.

\section{References}

1) Raybould, H. E., Nutrient Tasting and Signaling Mechanisms in the Gut I. Sensing of lipid by the intestinal mucosa. Am. J. Physiol. Gastrointest. Liver. Physiol., 277, G751-G755 (1999).

2) Furness, J. B., Kunze, W., and Clerc, N., Nutrient tasting and signaling mechanisms in the gut II. The intestine as a sensory organ: neural, endocrine, and immune responses. Am. J. Physiol. Gastrointest. Liver. Physiol., 277, G922-G928 (1999).

3) Buchan, A., Nutrient tasting and signaling mechanisms in the gut III. Endocrine cell recognition of luminal nutrients. Am. J. Physiol. Gastrointest. Liver. Physiol., 277, G1103-G1107 (1999).

4) Beucher, S., Levenez, F., Yvon, M., and Corring, T., Effects of gastric digestive products from casein on cck release by intestinal cells in rat. J. Nutr.
Biochem., 5, 578-584 (1994).

5) Nishi, T., Hara, H., and Kasai, T., Guanidinated casein hydrolysate stimulates pancreatic secretagogue release by direct action to the intestine in rats. Proc. Soc. Exp. Biol. Med., 218, 357-364 (1998).

6) Cordierbussat, M., Bernard, C., Haouche, S., Roche, C., Abello, J., Chayvialle, J. A., and Cuber, J. C., Peptones stimulate cholecystokinin secretion and gene transcription in the intestinal cell line stc-1. Endocrinology, 138, 1137-1144 (1997).

7) Nemozgaillard, E., Bernard, C., Abello, J., Cordierbussat, M., Chayvialle, J. A., and Cuber, J. C., Regulation of cholecystokinin secretion by peptones and peptidomimetic antibiotics in stc-1 cells. Endocrinology, 139, 932-938 (1998).

8) Habeeb, A., A new reagent for guanidination of proteins. Can. J. Biochem. Physiol., 38, 493-501 (1960).

9) Hara, H., Nishi, T., and Kasai, T., A protein less sensitive to trypsin, guanidinated casein, is a potent stimulator of exocrine pancreas in rats. Proc. Soc. Exp. Biol. Med., 210, 278-284 (1995).

10) Bjorkman, D. J., Allan, C. H., Hagen, S. J., and Trier, J. S., Structural features of absorptive cell and microvillus membrane preparations from rat small intestine. Gastroenterology, 91, 1401-1414 (1986).

11) Johnston, G. A. and Freeman, H. J., The effects of different membrane isolation and purification techniques on D-glucose transport into rat brush-border membrane vesicles. Can. J. Physiol. Pharmacol., 66, 1355-1360 (1988).

12) Lofas, S. and Johnsson, B., A novel hydrogel matrix on gold surface in surface plasmon resonance sensors for fast and efficient covalent immobilization of ligands. J. Chem. Soc. Chem. Commun., 21, 1526-1528 (1990).

13) Johnsson, B., Lofas, S., and Lindquist, G., Immobilization of proteins to a carboxymethyldextranmodified gold surface for biospecific interaction analysis in surface plasmon resonance sensors. Anal. Biochem., 198, 268-277 (1991).

14) Horio, T. eds., In "Theory and practice on enzymes and other proteins", eds., Nankodo, Tokyo. (1994).

15) Green, G. M. and Lyman, R. L., Feedback regulation of pancreatic enzyme secretion as a mechanism for trypsin inhibitor-induced hypersecretion in rats. Proc. Soc. Exp. Biol. Med., 140, 6-12 (1972).

16) Green, G. M., Feedback inhibition of cholecystokinin secretion by bile acids and pancreatic proteases. $A n$ nal. N. Y. Acad. Sci., 713, 167-179 (1994).

17) Owyang, C., Negative feedback control of exocrine pancreatic secretion: role of cholecystokinin and cholinergic pathway. J. Nutr., 124, 1321S-1326S (1994).

18) Fushiki, T. and Iwai, K., Two hypotheses on the feedback regulation of pancreatic enzyme secretion. Faseb J., 3, 121-126 (1989).

19) Herzig, K. H., Schon, I., Tatemoto, K., Ohe, Y., Li, Y., Folsch, U. R., and Owyang, C., Diazepam binding inhibitor is a potent cholecystokinin-releasing peptide in the intestine. Proc. Natl. Acad. Sci. U.S. A., 93, 7927-7932 (1996).

20) Spannagel, A. W., Green, G. M., Guan, D. F., Liddle, R. A., Faull, K., and Reeve, J. R., 
Purification and characterization of a luminal cholecystokinin-releasing factor from rat intestinal secretion. Proc. Natl. Acad. Sci. U. S. A., 93, 4415-4420 (1996).

21) Yamanishi, R., Kotera, J., Fushiki, T., Soneda, T., Saitoh, T., Oomori, T., Satoh, T., and Sugimoto, E., A specific binding of the cholecystokinin-releasing peptide (monitor peptide) to isolated rat small-intestinal cells. Biochem. J., 291, 57-63 (1993).

22) Yamanishi, R., Kotera, J., Fushiki, T., Senda, T., Iwanaga, T., and Sugimoto, E., Characteristic and localization of the monitor peptide receptor. Biosci. Biotechnol. Biochem., 57, 1153-1156 (1993).

23) McVey, D. C., Romac, J., Clay, W. C., Kost, T. A., Liddle, R. A., and Vigna, S. R., Monitor peptide binding sites are expressed in the rat liver and small intestine. Peptides, 20, 457-464 (1999).

24) Cuber, J. C., Bernard, G., Fushiki, T., Bernard, C., Yamanishi, R., Sugimoto, E., and Chayvialle, J. A., Luminal CCK-releasing factors in the isolated vascularly perfused rat duodenojejunum. Am. J. Physiol. Gastrointest. Liver. Physiol,, 259, G191-G197 (1990).

25) Hara, H., Narakino, H., and Kiriyama, S., Enhancement of pancreatic secretion by dietary protein in rats with chronic diversion of bile-pancreatic juice from the proximal small intestine. Pancreas, 9, 275-279 (1994).

26) Hira, T., Hara, H., and Aoyama, Y., Stimulative effect of a casein hydrolysate on exocrine pancreatic secretion that is independent of luminal trypsin inhibitory activity in rats. Biosci. Biotechnol. Biochem., 63, 1192-1196 (1999).

27) Liddle, R. A., Green, G. M., Conrad, C. K., and
Williams, J. A., Proteins but not amino acids, carbohydrates, or fats stimulate cholecystokinin secretion in the rat. Am. J. Physiol. Gastrointest. Liver. Physiol., 251, G243-G248 (1986).

28) Guan, D. F. and Green, G. M., Significance of peptic digestion in rat pancreatic secretory response to dietary protein. Am. J. Physiol. Gastrointest. Liver. Physiol., 271, G42-G47 (1996).

29) Schneeman, B. O. and Lyman, R. L., Factors involved in the intestinal feedback regulation of pancreatic enzyme secretion in the rat. Proc. Soc. Exp. Biol. Med., 148, 897-903 (1975).

30) Hira, T., Hara, H., and Kasai, T., Stimulation of exocrine pancreatic secretion by soybean trypsin inhibitor does not depend on the masking of luminal tryp$\sin$ activity in rats that have bile-pancreatic juice diverted into the ileum. Pancreas, 15, 285-290 (1997).

31) Powers, J. C. and Harper, J. W., Inhibitors of metalloproteases. In "Proteinase inhibitors", eds. A. J. Barret and G. Salvesen, Elsevier science, Amsterdam, pp. 219-298 (1986).

32) Grant, G., Edwards, J. E., Ewan, E. C., Murray, S., Atkinson, T., Farningham, D. A., and Pusztai, A., Secretion of pancreatic digestive enzymes induced in rats by first-time oral exposure to kidney bean E2L2 lectin is mediated only in part by cholecystokinin (CCK). Pancreas, 19, 382-389 (1999).

33) Jordinson, M., Goodlad, R. A., Brynes, A., Bliss, P., Ghatei, M. A., Bloom, S. R., Fitzgerald, A., Grant, G., Bardocz, S., Pusztai, A., Pignatelli, M., and Calam, J., Gastrointestinal responses to a panel of lectins in rats maintained on total parenteral nutrition. Am. J. Physiol. Gastrointest. Liver. Physiol., 39, G1235-G1242 (1999). 